\title{
Biochemical Markers and Pathological Features of Postmortem Time Interval Distinguishing Freshwater and Saltwater Drowing Induced Death in Albino Rats
}

\author{
Mahmoud M Elalfy ${ }^{*}$, Hadeer H Ragheb ${ }^{1}$, Mohamed F Hamed ${ }^{2}$ and Fathy R Sleem ${ }^{1}$ \\ ${ }^{1}$ Forensic medicine and toxicology faculty of veterinary medicine, Egypt \\ ${ }^{2}$ Pathology department faculty of veterinary medicine, Egypt
}

*Corresponding author: Mahmoud Elalfy, Forensic medicine and toxicology faculty of veterinary medicine, Mansoura university, 35516 Egypt 60-Elgomhouria Street, Mansoura City, Egypt

\section{ARTICLE INFO}

Received: 㓞 July 17, 2019

Published: 慧 July 23, 2019

Citation: Mahmoud M Elalfy, Hadeer H Ragheb, Mohamed F Hamed, Fathy R Sleem. Biochemical Markers and Pathological Features of Postmortem Time Interval Distinguishing Freshwater and Saltwater Drowing Induced Death in Albino Rats. Biomed J Sci \& Tech Res 20(1)-2019. BJSTR. MS.ID.003382.

Keywords: Freshwater; Saltwater; Drowning; PMI; Biochemical Markers; Collagen; IL-6

\begin{abstract}
Identification of drowning in freshwater or saltwater still controversial. The recovered bodies form water and movement of cadavers made the task of differentiation of two types of drowning so difficult. To better understand the pathophysiology and PMI changes in drowning, we use 36 albino rats were exposed to induction of drowning in freshwater and or saltwater and recovered bodies were kept to 24 or $48 \mathrm{hrs}$ for checking the changeable PMI markers between fresh or saltwater. Notably, brain of saltwater drowning show severe vacuolation in the brain parenchyma, heart is showing death of cardiomyocytes and increases in the interstitial spaces and lung displays pulmonary atelectasis and over distended alveoli with air with rupture of capillaries and cellular death of interstitial cells. While this pathological feature in freshwater is less prominent than saltwater. Fresh water drowned rats showed an increase in level of LDH, Albumin, total protein, sodium, potassium and chloride in postmortem time dependent manner.
\end{abstract}

Notably, cholesterol and CPK were fluctuated levels in fresh water drowned rats and levels of triglycerides and calcium were time dependent decreased. However, drowning in saltwater, retard analysis and protein degradation in first 24 after rat's corpse recovered from water, then again started with evidence of increase total protein and albumin. While LDH and sodium were increased until 24hrs and then decreased. Moreover, there were a time dependent increase of triglycerides, CPK and calcium in postmortem drowned rats in saltwater and decreased the level of cholesterol, potassium and chloride in the water drowned rats. Intriguing, that collagen deposition and immunostaining reaction of IL-6 considered as a good marker for differentiation of tissue of lung and heart between different causes of death as it increased in saltwater $>$ fresh $>$ natural induced death. In conclusion, biochemical markers of PMI are causes of death dependent and could differ from case to another.

\section{Introduction}

Drowning is the type of violent asphexia of respiratory dysfunction from submersion/immersion in liquid resulted in death [1-4]. Diagnosis of the drowning of recovered animals from fresh water is very important in forensic medicine, legal and insurance [3]. There several effects of drowning on the corpse of drowned rats. The organ weights for the lung and brain of drowned rats were increased in the experimental drowning group compared to 24-hour post-mortem immersion group. while the mean heart weight was not [5]. Differentiation between fresh water and saltwater drowning on forensic medicine still controversial [6] as the external examination and the corpse gross findings are in most of the reported cases not specific and there are no clear laboratory investigations for diagnosis of drowning especially when dead is moved away of water resources (Figure 1). The diagnosis of drowning considers one of the major issues in forensic medicine, especially when there is a delay in recovering the case [7]. The diagnosis of drowning based on pathological changes is often a difficult task, as the typical features of pulmonary edema 
and congestion are nonspecific [8,9]. Recently, immune-reactive proteins like IL-6, aqp5 and others were used for identification of bodies recovered from seawater [10-14]. The rationale of this study is exploring that biochemical and cytokines could be distinguished seawater and freshwater drowning and these changes may be differing when cause of death is changed and so biochemical marker still controversial up to now.

\section{Materials and Methods}

Animal procedures were conducted with the accordance of the animal care committee of the ethics Board of the faculty of veterinary medicine Mansoura university, Egypt. 36 male Albino rats (weight, 150-200GM was purchased from faculty of pharmacy, Mansoura University, Egypt). They were managment on a 12-h light-dark cycle with available of food and water for ad libitium (Figure 2). Rats were exposed to drowning by keeping them in a wire box in collected freshwater (Egyptian nil river) or saltwater (mediterranean sea). Time from start of drowning till complete death was recorded. Recovered dead rats were kept in fixed supine position on research lab. Temperature (20oC) for $48 \mathrm{hrs}$ hours postmortem. Blood samples of each 6 rats for each time point were collected from heart and great vessels at autopsy [15] and suffer postmortem changes in 0, 24 and $48 \mathrm{hrs}$ hours. Samples were centrifuged immediately for $20 \mathrm{~min}$ at $2000 \mathrm{rpm}$. Serum samples was stored at -20 deep freezer until measurement (Figure 3).

\section{Histopathology Examination}

The 12 male rats were anesthetized with thiopental and natural death was induced [16]. 24 recovered corpse of drowned rats were kept for 0, 24 and 48hrs and their tissues like heart, lung, and brain were separated at different time point after death and fixed at $10 \%$ neutral buffered formalin. Fixed tissue were procedures were described previously before in details for eosin and hematoxylin staining [17].

\section{Immunohistochemically localization IL-6}

The tissue of brain, heart and lung paraffin sections that were mounted on positively charged glass slides were processed for single immunohistochemistry with an antibody to IL-6 according to method described earlier [18]. The mean area percentage of collagen fiber content between the brain, heart and lung of drowned rats either in fresh water or slat water was quantified for each group. Atomic absorption spectrometry analysis of stomach content of trace mineral in fresh and saltwater drowning (Figure 4). The collected stomach content was collected after recovered rats from water either fresh or salt one. The samples were kept in polyethylene bags till digestion step by acid. Liquid digestion: All samples were digested by acid mixture. the mixture of NitricPerchloric acids were used in the liquid digestion of samples (Sigma-Aldrich, Egypt). Combined acids (10 mL, 65\% high purity HNO3 and 3:1 v/v) was added to the beaker containing $2 \mathrm{~g}$ fresh meat for liquid digestion of samples (Figure 5).

\section{Statistical Analysis}

Statistical analysis was carried out using the student's t-test and one way annova. $\mathrm{P}<0.05$ was considered significant [19] (spss version13).

\section{Results}

\section{Pathological Features of Fresh Water Drowning}

Immediately after drowning, the brain is showing scattered neurons with pyknotic nuclei of neurons and minute vacuolation in the brain parenchyma, heart is showing normal cardiomyocytes and normal interstitial capillaries and Lung displays overdistension of pulmonary alveoli meanwhile a lot of alveoli showing atelectasis and normal interstitial tissue. After $24 \mathrm{hrs}$ after confirmed drowning, the brain is showing a loss of cytoplasm and pyknotic nuclei of neurons, and vacuolation in the brain parenchyma, heart is showing decrease size of cardiomyocytes and relatively increase in interstitial spaces and lung displays postmortem changes represented by pyknotic and dissolution interstitial cells with rupture the wall of blood capillaries. After $48 \mathrm{hrs}$ of confirmed drowning, the brain is showing loss of cytoplasm and pyknotic nuclei of neurons, and vacuolation in the brain parenchyma, heart is showing postmortem changes represented by decrease size and loss of cytoplasm of cardiomyocytes and loss of adipocytes around myocardium with neutrophils and lung displays postmortem changes represented by diffuse pyknotic interstitial support cells and pneumocytes with dissuade atelectasis (Figure 1).

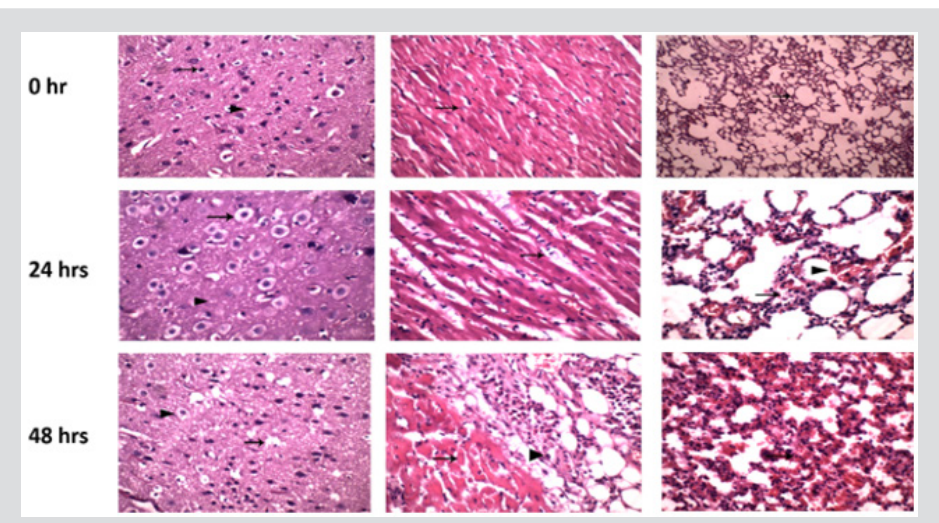

Figure 1: Show pathological features of fresh water drowning at 24 and 48 hrs. of neuron, cardiomyocytes death and rupture of alveoli. 


\section{Pathological Features of Salt water Drowning}

Immediately after recovering dead rat from saltwater, the brain is showing angular shaped neurons, and minute vacuolation in the brain parenchyma, Heart is showing normal cardiomyocytes and slightly increases in interstitial spaces and lung displays over distended alveoli with air with cellular death and desquamation of intrapulmonary bronchiole. After $24 \mathrm{hrs}$, the brain is showing postmortem changes represented by death of neurons (arrow), and vacuolation in the brain parenchyma, heart is showing normal cardiomyocytes and slightly increases in interstitial spaces, lung displays over distended alveoli with air with death pneumocytes with rupture of capillaries and cellular death of interstitial cells. After $48 \mathrm{hrs}$, the brain is showing postmortem changes represented by death of neurons, and severe vacuolation in the brain parenchyma, heart is showing death of cardiomyocytes and increases in interstitial spaces, lung displays pulmonary atelectasis and over distended alveoli with air with rupture of capillaries and cellular death of interstitial cells (Figure 2).

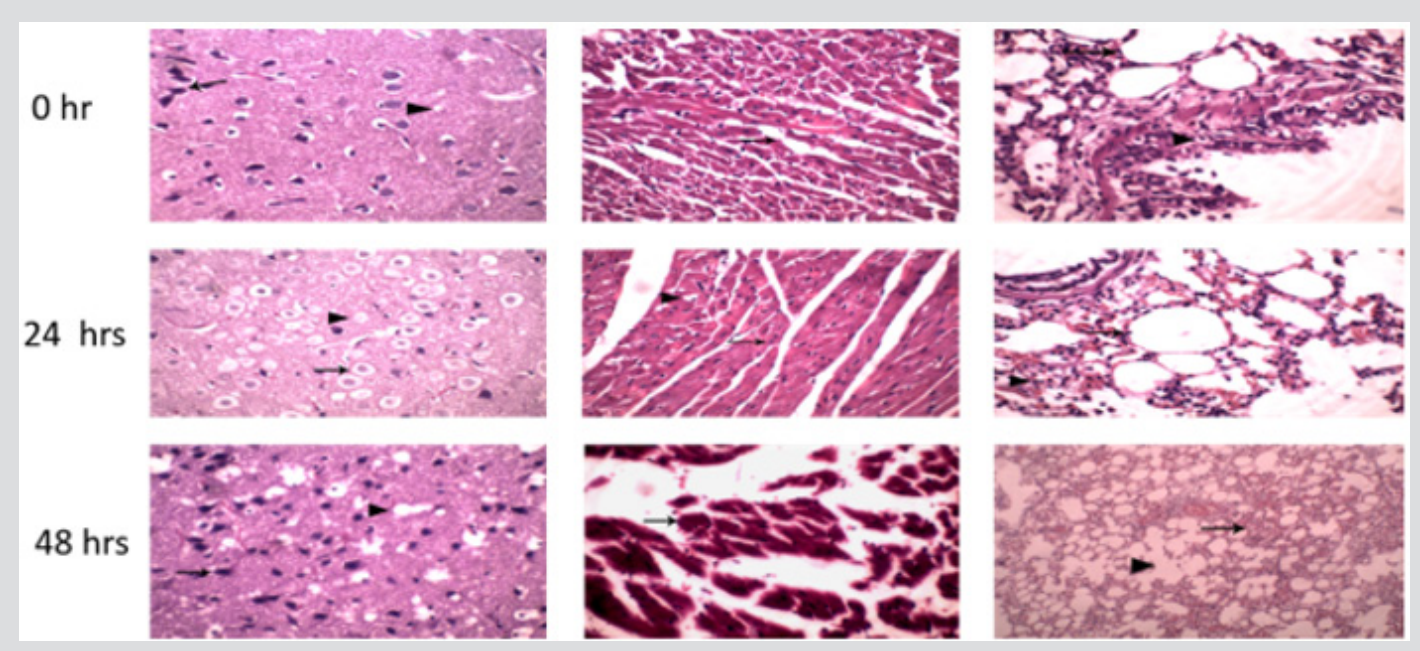

Figure 2: Show pathological feature of salt water drowning in rats, the brain is showing changes represented by death of neurons, and marked vacuolation in the brain parenchyma, heart is showing death of cardiomyocytes and increases in interstitial spaces, lung displays pulmonary atelectasis and over distended alveoli with air with rupture of capillaries and cellular death of interstitial cells at $48 \mathrm{hrs}$ than $24 \mathrm{hrs}$.

\section{Biochemical Marker Distinguished Between Fresh and}

\section{Saltwater Drowning}

Fresh water drowned rats showed an increase in level of LDH, Albumin, total protein, sodium, potassium and chloride in postmortem time dependent manner (Figues 3 \& 4). Notably, cholesterol and CPK were fluctuated levels in fresh water drowned rats and levels of triglycerides and calcium were time dependent decreased.

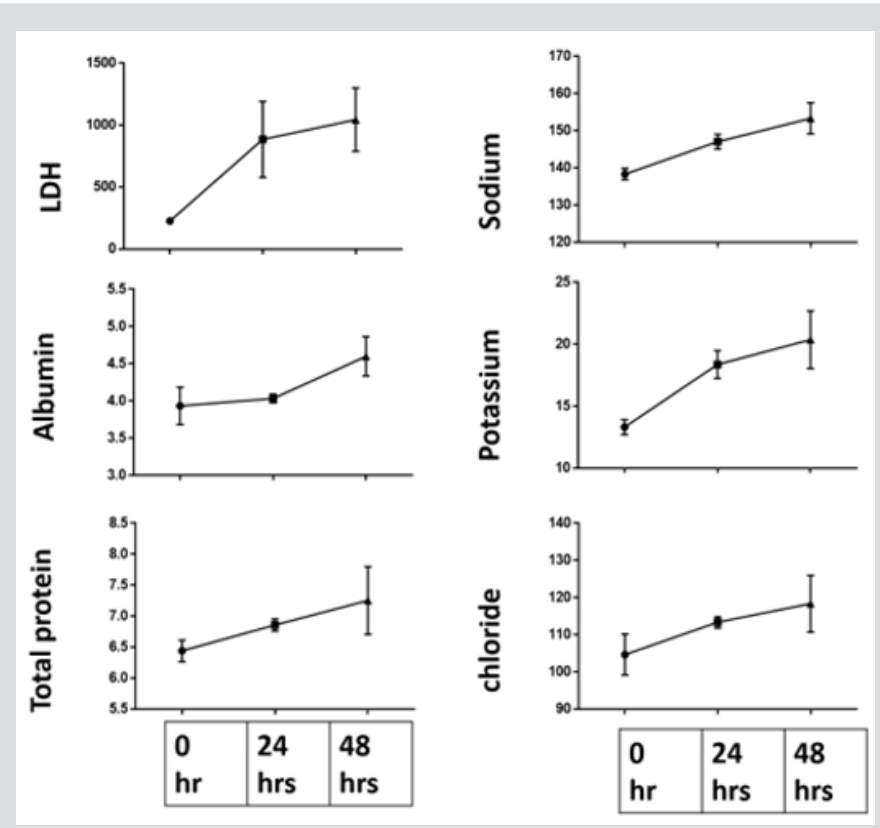

Figure 3: Show dependent increase of LDH, albumin, total protein, potassium, sodium, and chloride level. 

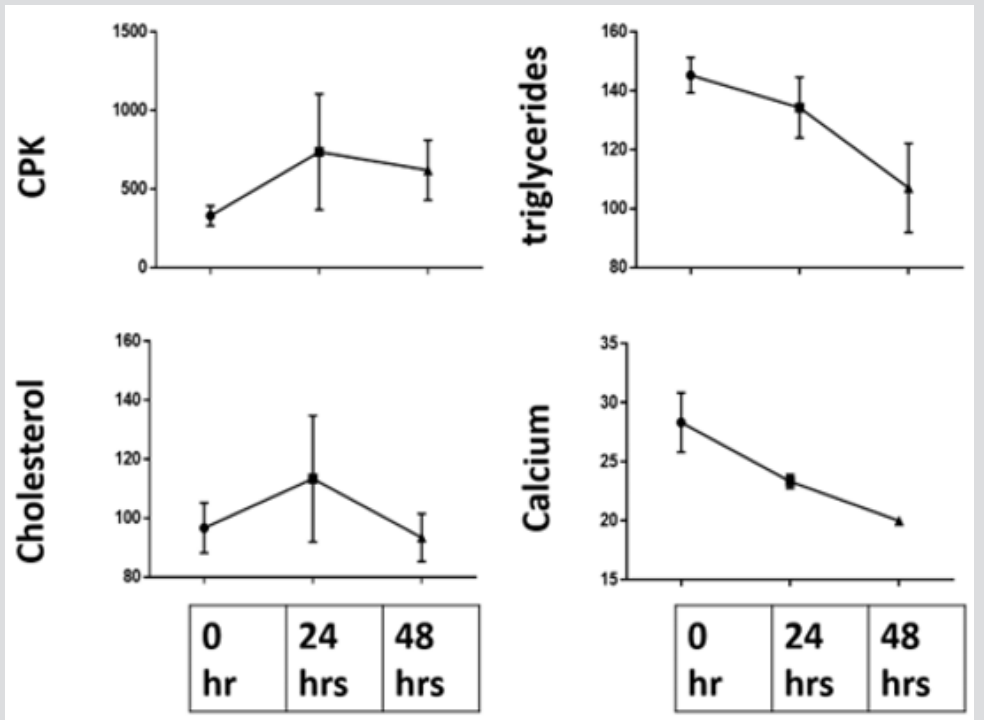

Figure 4: Show that cholesterol and CPK were fluctuated levels in fresh water drowned rats and levels of triglycerides and calcium were time dependent decreased.

\section{Biochemical modulation in drowned rats in saltwater drowning}

Notably, drowning in saltwater retard autolysis and protein degradation in first 24 after rat's corpse recovered from water then again started with evidence of increase total protein and albumin. While LDH and sodium were increase until $24 \mathrm{hrs}$ and then decreased. Moreover, there were time dependent increase of triglycerides, CPK and calcium in postmortem drowned rats in saltwater and decreased the level of cholesterol, potassium and chloride in the water drowned rats (Figures $5 \& 6$, 7). Collagen deposition and reactive IL-6 in natural induced death and drowned rats in fresh and saltwater drowned. It was notice that collagen deposition and immunostaining reaction of IL-6 considered as good marker for differentiation of tissue of lung and heart between different causes of death as it increased in saltwater $>$ fresh $>$ natural induced death (Figures 8 \& 9). Heavy and trace element measurement by atomic absorption spectrometry Stomach content was evident in all rats and in all times in postmortem analysis. Level of cadmium, lead and calcium were significant increase only in salt water drowning when compared with natural death and fresh water drowning. While level of potassium was decreased in both fresh water and saltwater drowning when compared to natural induced brain stem death $[19,20]$ Figure 10.

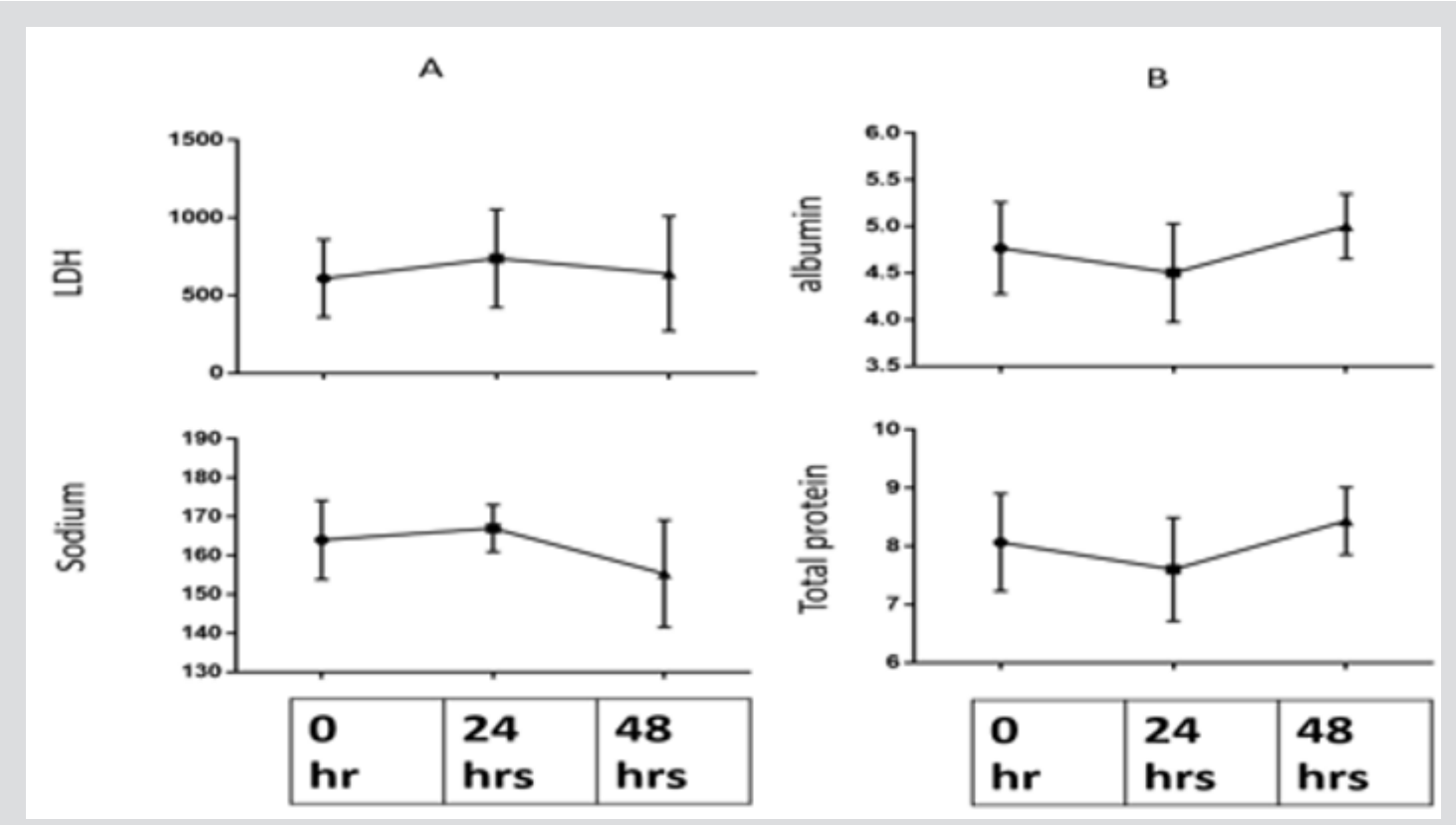

Figure 5: Show fluctuated biochemical up and down in A. and B. with evidence that saltwater delay protein degradation in first 24 hrs. only. 


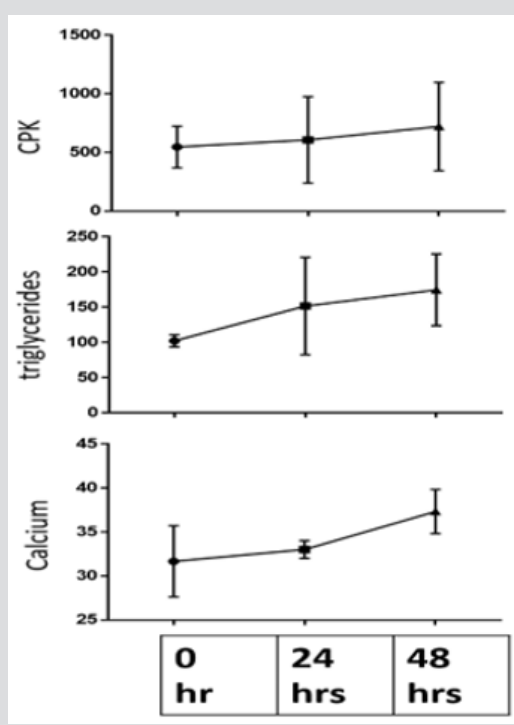

Figure 6: Show time dependent increase of triglycerides, CPK and calcium in postmortem drowned rats in saltwater.
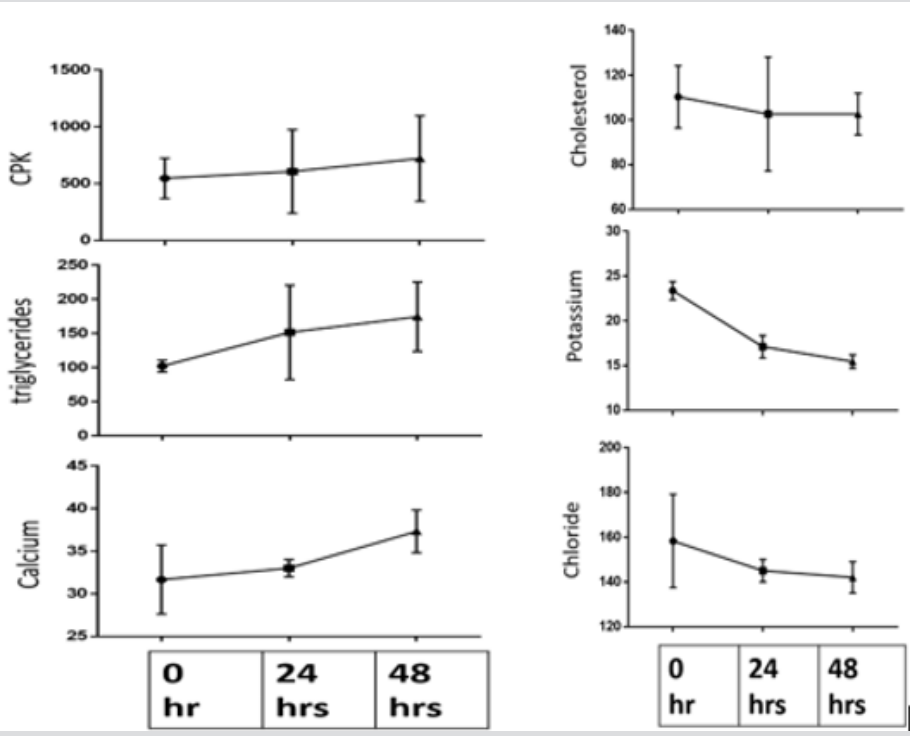

Figure 7: Show time dependent decrease in level of cholesterol, potassium and chloride in the water drowned rats.

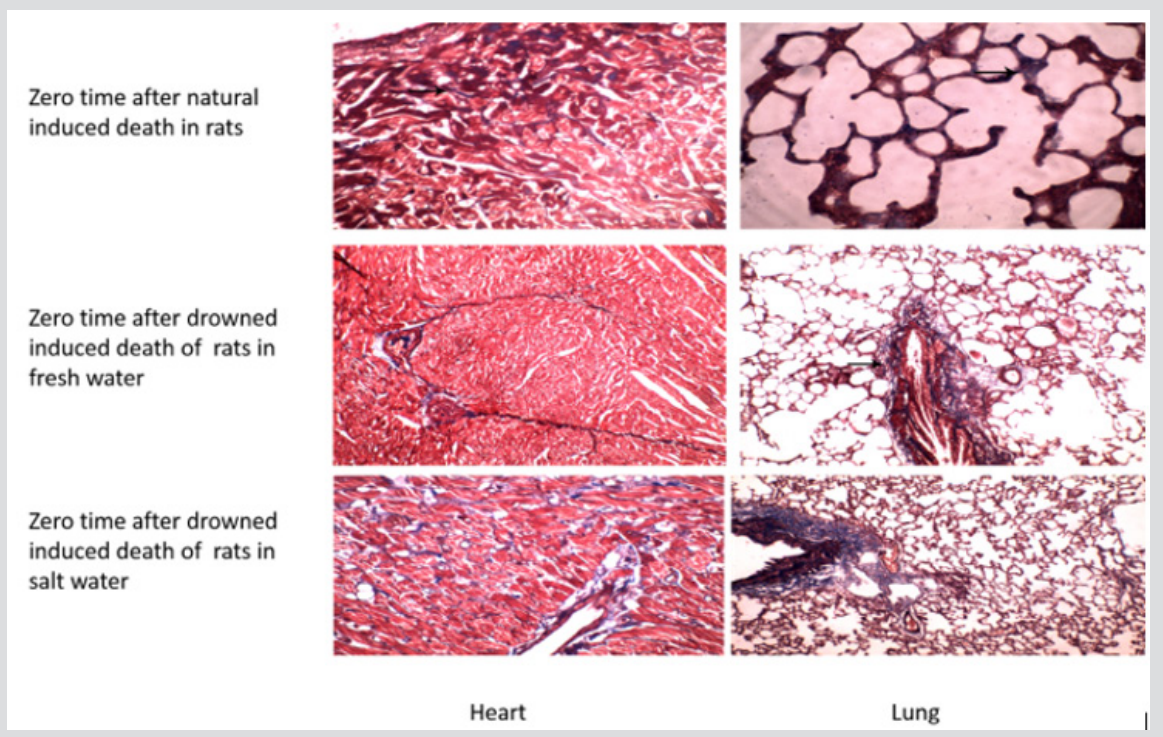

Figure 8: Show collagen deposition was increased significantly in salt water drowned lung and heart when compared with fresh water and natural induced rats immediately after induction of death. 


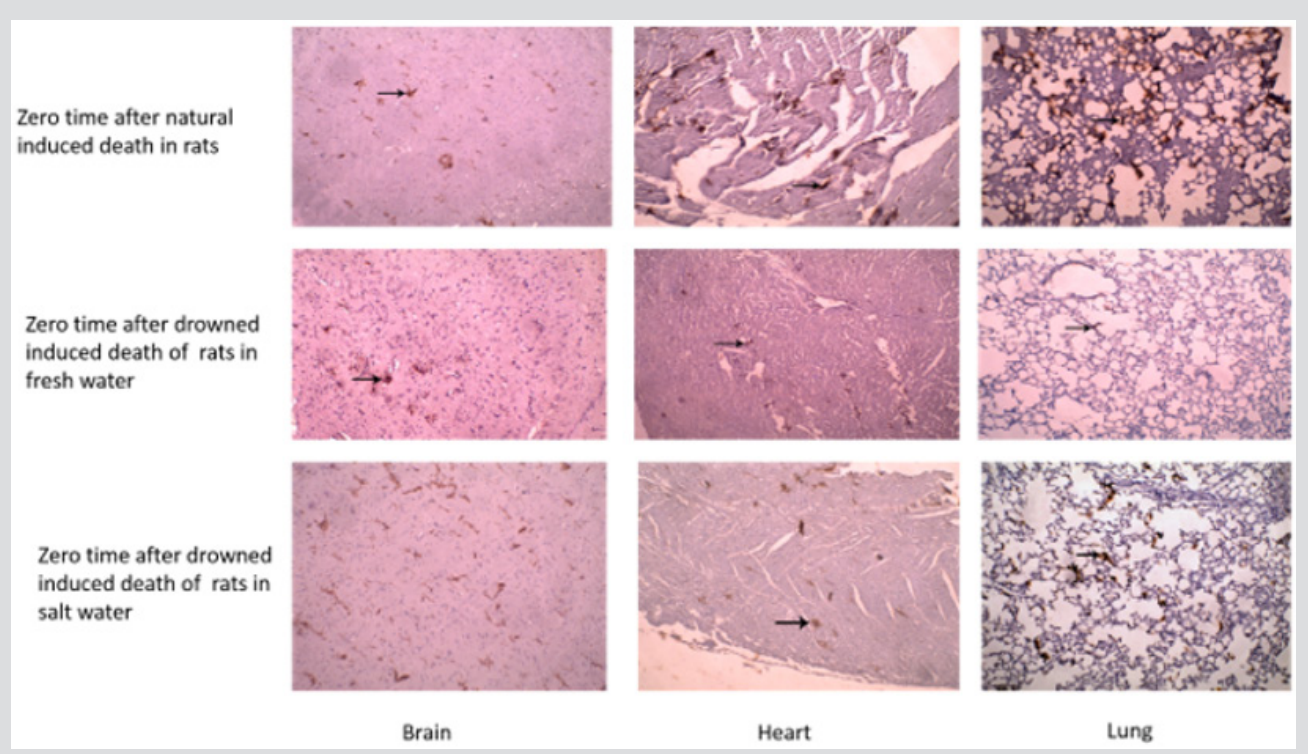

Figure 9: Show IL-6 was increased significantly in salt water drowned lung and heart when compared with fresh water and natural induced rats immediately after induction of death.

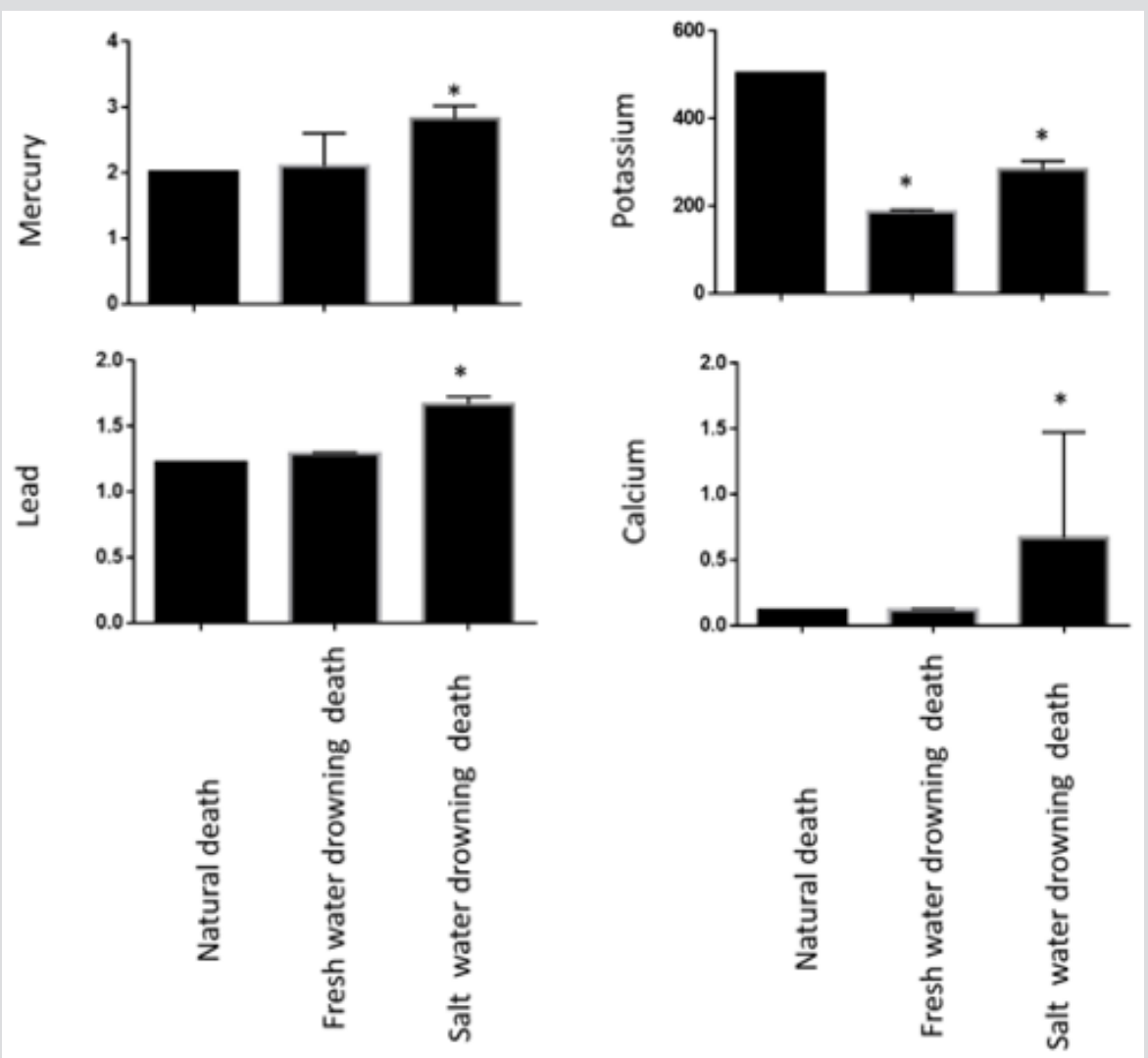

Figure 10: Marked increase of cadmium, lead and calcium in stomach content of saltwater drowned rats than freshwater. While notable decreased in level of potassium in both freshwater and seawater drowned rats.

\section{Discussion}

The distinguishing between salt and fresh water drowning and other causes of death are very important in forensic medicine for both criminal and civil conditions especially when recorded the movement of recovered corpse after extracted from water. Differentiation between fresh water and salt water drowning on forensic medicine still controversial (20 and 6) as the gross examination and the corpse pathological findings are in most of the reported cases not specific and there were no clear laboratory investigations for diagnosis of drowning especially when cadaver was moved away of water resources. The distinguishing between salt and fresh water drowning and other causes of death are very 
important in forensic medicine for both criminal and civil conditions especially when recorded the movement of recovered corpse after extracted from water. As autolysis could remove or cancel the effect of water on extracted cadaver.

Notably, biochemical, trace mineral, heavy metal of stomach content, histopathology, collagen and IL-6 share a difference in fresh water and more prominent in salt water than those recorded in natural induced experimental rats. There is significant linear correlation between creatine kinase (CPK) and calcium with the time of blood putrefaction [21] similar to what recorded at $72 \mathrm{hrs}$ postmortem. Notably, the increase in the serum calcium level was observed in freshwater drowning [22]. the Postmortem changes started earlier in the heart 3 to 4 hours compared with other organs after death [23]. While collagen deposition at onset of death is prominent factor for diagnosis of death especially in drowning cases in forensic Autopsies [24]. Up with standing with current detection of abundance of IL-6 in tissues of seawater drowned rats than freshwater as seen previously $[10,13]$. Finally, as biochemical markers and trace mineral different in vitreous humor in seawater and freshwater [25] also could be differ in blood.

\section{Conclusion}

Changes of biochemical of postmortem times may dependent on cause of death and notably IL-6 expression could distinguish freshwater and seawater drowning.

\section{References}

1. Moon RE, Long RJ (2002) Drowning and near drowning. Emergency Medicare (Fremantle) 14(4): 377-386.

2. Idris AH, Berg RA, Bierens J, Bossaert L, Brancheet CM, et al. (2003) Recommended guidelines for uniform reporting of data from drowning. The "Utstein style" Circulation 108(20): 2565-2574.

3. Beeck EF Van, Branche CM, Szpilman D, Modell JH, Bierens JJ (2005) A new definition of drowning: towards documentation and prevention of a global public health problem. World Heal Organization 83(5): 853-856.

4. Mc Ewen BJ, Gerdin J (2016) Veterinary Forensic Pathology: Drowning and Bodies Recovered From Water. Ventry Pathology 53(5): 1049-1056.

5. Kul CG, Balcı Y, Yorulmaz C, Uzuner K, Öner S, et al. (2011) The effects of experimental fresh water drowning on the organ weights of the lungs, livers, brains, hearts and kidneys of rats. Adli Tıp Bülteni 16(1): 8-13.

6. Piette MHA, De Letter EA (2006) Drowning: still a difficult autopsy diagnosis. Forensic Science Institute 163(1-2): 1-9.

7. Knight B (2004) Forensic Pathology. ( ${ }^{\text {rd }}$ edn.) Arnold, London, UK, pp: 1-395.

8. Byard Roger W, Summersides Glenda (2011) Vitreous Humor Sodium Levels in Immersion Deaths. J Forensic Science 56(3): 643-644.

9. Marell Gian Luca, Feola Alessandro, Marsell Luigi Tonino, Mauriell Silvestroo, Giugiano Pasquale, et al. (2019) Diagnosis of drowning, an everlasting challenge in forensic medicine: review of the literature and proposal of a diagnostic algorithm. Acta Medica Mediterranea 35(1): 900-919.
10. Zhang Y, Zhang B, Xu DQ, Li WP, Xu Met, et al. (2011) Tanshinone IIA attenuates seawater aspirationinduced lung injury by inhibiting macrophage migration inhibitory factor. Biol Pharm Bull 34(7): 10521057.

11. Fan Q Zhao P, Li J, Xie X, Xu M, et al. (2011) 17ßEstradiol administration attenuates seawater aspirationinduced acute lung injury in rats. Pulmbmed Pharmacology Therapy 24: 673681.

12. Li J, Xu M, Fan Q Xie X, Zhang Y, et al. (2011) Tanshinone IIA ameliorates seawater exposureinduced lung injury by inhibiting aquaporins (AQP) 1 and AQP5 expression in lung. Responsive Physiological Neurobiology 176(1-2): 3949.

13. Liu Z, Xi R, Zhang Z, Li W, Liu Y, et al. (2014) X: 4hydroxyphenylacetic acid attenuated inflammation and edema via suppressing HIF1 $\alpha$ in seawater aspirationinduced lung injury in rats. International Journal of Molecular Science 15(7): 1286112884.

14. Hayashi Takahito, Ishida Yuko, Mizunuma Shinya, Kimura Akihiko, Kondo Toshikazu (2009) Differential diagnosis between freshwater drowning and saltwater drowning based on intrapulmonary aquaporin-5 expression. International Journal of Legal Medicine 123: 7-13.

15. Uemura K, Shintani Ishida K, Saka K, Nakajima M, Ikegaya H, et al. (2008) Biochemical blood markers and sampling sites in forensic autopsy. Journal of Forensic Legal Medicine 15(5): 312-317.

16. Zhang S, Cao S, Wang T, Yan B, Lu Y, et al. (2014) Modified brain death model for rats. Explanation Clinical Transplant 12(5): 469-473.

17. Bancroft JD, Gamble M (2002) Theory and practice of histological techniques. ( $5^{\text {th }}$ edn.) Philadelphia: Churchill Livingstone.

18. Benmehdi H, Allali H, Tabti B, Djabou N, Bendiabdellah A, et al. (2002) sensitivity of a novel Biotin-free detection reagent (power vision) for immunohistochemistry. Journal of Histotechnology 25(4): 247-250.

19. Snedecor GW, William CG (1989) Statistical Methods, ( $8^{\text {th }}$ edn.), Iowa, State University Press, USA.

20. Hansen Ida Borg, Thomsen Asser Hedegard (2018) Circumstances and autopsy findings in drownings, Department of Forensic Medicine, Aarhus University, 2006- 2015. Scandinavian journal of FORENSIC SCIENCE Nordisk rettsmedisin (1): 1-6.

21. Costa Isabel, Carvalho Félix, Magalhães Teresa, Guedes De Pinho Paula, Silvestre Ricardo, et al. (2015) Dinis-Oliveira Jorge Ricardo. Promising blood-derived biomarkers for estimation of the postmortem interval. Toxicology Residence 4: 1443-1452.

22. Zhu Bao Li, Ishikawa Takaki, Quan L, Li DR, Zhao D, et al. (2004) Evaluation of Postmortem Serum Calcium and Magnesium Levels in Relation to the Causes of Death in Forensic Autopsy Forensic Science International 155(1): 18-23.

23. Abo El Noor Mona Mohamed, Elhosary Naema Mahmoud, Khedr Naglaa Fathi, El Desouky Kareema Ibraheem (2016) Estimation of Early Postmortem Interval Through Biochemical and Pathological Changes in Rat Heart and Kidney. Am J Forensic Med Pathology 37(1).

24. Urer Halide Nur, Ersoy Gokhan, Yllmazbayhan Emine Dilek (2012) Diffuse Alveolar Damage of the Lungs in Forensic Autopsies: Assessment of Histopathological Stages and Causes of Death the Scientific World Journal p: 1-6.

25. Ragheb HH, Elalfy MM, Ali FR (2019) Biochemicals and DNA degradation identifier markers of postmortem time interval in different causes of death. vet nary Open Access Journal 1(1): 1-11. 
ISSN: 2574-1241

DOI: 10.26717/BJSTR.2019.20.003382

Mahmoud M Elalfy. Biomed J Sci \& Tech Res

(c) (9) This work is licensed under Creative Commons Attribution 4.0 License

Submission Link: https://biomedres.us/submit-manuscript.php

$\begin{array}{ll}\text { BIOMEDICAL } & \text { Assets of Publishing with us } \\ \text { RESEARCHES } & \text { - Global archiving of articles } \\ & \text { - Immediate, unrestricted online access } \\ & \text { - Rigorous Peer Review Process } \\ \end{array}$

